\title{
About Cultivation of Innovative Talents in Knowledge-Based Enterprises
}

\author{
XU Shanshan \\ No.37 Daoyi South Avenue, Daoyi Development District, Shenyang \\ Aerospace University, School of Economics \& Management, China 110136
}

\begin{abstract}
In the era of knowledge economy, modern enterprises are the main body of independent knowledge innovation, while knowledge innovation capability of innovative talents is one of the most important competitiveness in knowledge-based enterprises. Thus, the cultivation of innovative talents is a prerequisite for independent knowledge innovation of enterprises and also a key matter in the development of the enterprises. To improve the training design for innovative talents' knowledge innovation capability and then to establish an effective training mechanism in the knowledge-based enterprises is a cutting-edge issue in the management and development of human resources. It is only by enhancing and developing the overall knowledge of the innovative talents, can the enterprises make sustainable development in the fierce competition in the era of knowledge economy.
\end{abstract}

Keywords: cultivation, innovation talents, knowledge-based enterprises.

In the era of knowledge economy, knowledge innovation becomes a basic rule of survival for enterprises to deal with the fierce competition. Knowledge innovation has become the main source of the core competitiveness of enterprises, i.e. the success of an enterprise must result from the continuous knowledge innovation. The cultivation of innovative talents has become a key factor for the development of a knowledge-based enterprise.

Intellectual capital is a knowledgebased company's core resources. Intellectual capital is valuable knowledge that can bring the profits for the enterprise, and it is a part by which the enterprise's market value is higher than its book value. Thomas Stewart points out that intellectual capital includes human capital, structural capital and customer capital, while intelligence, which can be used to create value, is the major resources of a knowledge-based enterprise. Capital Stewart believes that the reason why a "knowledge-based" enterprise is named with "knowledge" is that knowledge is more important than any other factor inputs; in other words, employees' intellectual capital (such as knowledge and skills) dominates over physical capital or financial capital in an organization. The reason is that, in the era of knowledge economy, with an endless stream of new knowledge, knowledge will double about every seven years, and this cycle continues to shorten. "Talent", as the carrier of intellectual capital, becomes the most valuable capital of a knowledge-based enterprise, and the cultivation of innovative talents becomes an important factor to achieve the sustainable development of a knowledgebased enterprise. Therefore, in order to remain competitiveness and competitive advantages, a knowledge-based enterprise must devote oneself to develop its intellectual capital, cultivate innovative talents, 
and keep updating the existing knowledge, acquiring new knowledge from any possible sources, and constantly progressing knowledge innovation.

The development of a knowledgebased enterprise must rely on intellectual capital rather than physical capital, which is the main feature of a knowledge-based enterprise. Innovative talents refer to those people who are trying to change to lead the development through revolution, and thus make an outstanding contribution to the smooth transition in economy of the entire society. These people have some basic characteristics such as deep expertise attainments, a strong sense of responsibility, and courage to make changes. They are the key and rare resources to promote economic and social development. In today's world, the international competition is in fact the talent competition. To achieve development, a knowledge-based enterprise needs a lot of innovative talents as its support, and the talents have become the most important resource of a knowledge-based enterprise. Innovative talents are important for an enterprise not only because they can make full use of modern science and technology to improve efficiency, but more importantly, because they have the knowledge innovation capability, such as the capability to solve problems in an innovative way, to develop new technologies and to develop out new products. Their knowledge innovation capability is the source of a knowledge-based enterprise to obtain and maintain a sustainable competitive advantage. In order to make innovative talents create higher value, a knowledge-based enterprise must continue to develop and raise their knowledge innovation capability.

For a knowledge-based enterprise, innovative talents are the talents who have innovative foundation, innovation awareness and innovative approaches, and can get innovation achievement. In- novative talents are not born to be innovative, but mostly grow to be innovative after given proper learning and training. From the perspective of human resources training, after fully understanding the strategic position of training in the challenges of a competitive process, many knowledge-based enterprises, regardless of their sizes, have established a comprehensive training mechanism and system for innovative talents, providing a wider range of training programs and courses, which helps to inspire out valuable knowledge innovation vitality within the enterprise, and offers the possibility for developing knowledge innovation capacity of innovative talents. Cultivation of innovative talents in content mainly includes the following three aspects:

\section{Cultivation of Innovative Capacity}

Knowledge innovation is a creative practice activity, so an enterprise's innovation activities can succeed only with innovative capacity. Innovative capacity not refers to only one capacity, but includes a variety of capabilities, among which the five major aspects are:

1. Training of observing ability. Observation means that people feel external stimulus by the sensory organs, and gradually form impression with things and phenomenon around, and then understand the relationship between various phenomena and things. Keen observation is an essential basic capability for knowledge innovation talents. Employees' observing ability can be improved by such training as direct observation, indirect observation, qualitative observation, quantitative observation, etc.

2. Training of analysis capacity. Training of analysis capacity includes analysis via systems thinking, via basic issues, via proportion concept, via contingency thinking as well as via logic laws.

3. Imagination Training. Knowledge innovation can not be separated from the 
rich, powerful imagination. The training to strengthen the imagination includes the training of involuntary imagination, reproductive imagination, creative imagination, fantasy imagination, image imagination, sensory phenomenon, etc.

4. Training for extension of brain capacity. One person's idea in a certain period of time is always limited, but he can extend his brain by learning from the mind of others in order to explore new ideas in time and quickly get inspired. Such training includes making good use of the incentive, getting inspired by different industries, and searching classic and creative thinking.

5. Training of information acceptance. To cultivate the ability to receive information, one shall seize and think about valuable information, effectively gather any information which may help to solve any problems, and make an integrated use of innovative techniques to analyze and re-integrate elements of products and services. Meanwhile, he shall analyze and integrate information, and then think up some ideas by making full use of other innovative methods.

\section{Cultivation Raise of Innovation Awareness}

Innovation awareness triggers people's creative motivation according to the needs of development of the society and individual life, and refers to the intentions, desires and ideas that people show during creative activities. It is the starting point and the inherent power of people's creative activities, and also the premise of creative thinking and creativity, including four aspects:

1. Create innovation awareness. (1) Encourage innovation and also accept failure. In order to effectively generate knowledge innovation behavior in an enterprise, we must accept the consequences from the failure of employees' innovation while encouraging their innovative behavior, making bold and innovative spirit the essence of the enterprise's culture. (2) Try to find and ask questions. Find and propose one or a series of new and profound problems. (3) Brave to verify and deny the authority. The awareness of verifying and denying is the major difference between the innovators and mediocre ones.

2. Cultivate innovation awareness, creative thinking and perspective. Creativity is the best weapon for an enterprise to succeed. The cultivation of innovation awareness mainly include: cultivate the spirit of diligent for knowledge; cultivate creative, critical and unconventional questioning spirit; cultivate the innovation awareness with curiosity, imagination, suspicion and ability to seize the opportunities; finally cultivate exploration and research spirit with which one will think a lot about innovation and invention.

3. Training of awareness of knowledge sharing. In an enterprise, the implicit knowledge stored in the minds of employees is the source of the enterprise's knowledge innovation, which can keep a competitive advantage for the enterprise. The loss of core human resources of an enterprise, not only means the loss of talents, but also means the loss of the most important intellectual capital, while the maximum loss caused to the enterprise is technology leaks, loss of customer resources, market share transfer, etc. The human resources in a knowledge-based enterprise change frequently, so it is a very important issue to keep the intellectual capital of the human resources before they leave the enterprise. In order to achieve this, it is most necessary to manage the implicit knowledge of all human resources.

4. Training for a sense of cooperation and team innovation spirit. The close logical connections between knowledge decide the strong linkage between different nodes on an organization's value chain. A 
specific work, especially a knowledgebased work often requires team and project cooperation, i.e. it needs employees with a strong sense of cooperation and teamwork. Therefore, the training of a sense of cooperation and teamwork is necessary.

\section{Methods of Learning and Innova- tion}

The knowledge alone is of no value. Once the external conditions for learning are ready, employees must have methods of learning and knowledge innovation to continuously update and enrich their knowledge, and integrate the existing knowledge to consciously carry out knowledge innovation to create values for the enterprise, thus to achieve the purpose of knowledge management.

1. Training of image thinking. Image thinking is a form of thinking with thing's specific figures and images as the main content of thinking, That is, judge and get the essence of things and its law of motion through the understanding and analysis of the specific figures or images of things. The image of thinking ability can be improved by the right brain potential development, because the right brain helps to break various mindset, and then improve the imagination and thinking in images.

2. Training of divergent thinking. The divergent thinking is characterized in broad thinking sight and multidimensional divergent thinking. One important symbol of one's creativity is whether or not he can flexibly use the divergent thinking. A person's divergent thinking can be trained through combined divergence, lateral divergence, threedimensional divergence, information intercourse divergence and example divergence.

3. Training of association thinking. Association thinking acts as the wings of creativity and innovation. The more vast and abundant the association thinking is, the more creative ability one has. Training of association thinking mainly includes: similar associations, close associations, associations by contrast, and relations associations.

4. Reverse thinking. Reverse thinking is a way of thinking which is opposite to the conventional, logic and majority thinking. In an enterprise, reverse thinking is often a scientific way of thinking which can challenge the majority with minority and finally reach great achievements. The training of reverse thinking includes: inverted-reverse thinking, transformational reverse thinking, and determined reverse thinking.

5. Training of thinking ahead. Facing with a changing dynamic market, an enterprise can gain the initiative in the market competition only by improving its resilience, being prepared for danger in times of peace, and developing out new products ahead of needs. Thinking ahead is a way of thinking to adjust the reality by predicting the situations that may arise in the future. Thinking ahead has the role to: promote predictive thinking of prospects, and help adjust the development direction of the current conditions, which will help develop the right plan and target, and implement the right decisions.

\section{References}

[1] HAN Dayong, "Knowledge-based employee incentive strategy," Beijing, China Economic Press, pp.224-260, 2008.

[2] BAO Shuimei, LI Shiping, "Predicament and the root causes of our innovative talents training and the way out," Proc. Of the Modern education management, pp. 23-27, .2012(6).

[3] XU Shanshan, "Interaction between Knowledge Innovation \& Human Resources Training and Enterprise Development," Proc. Of the Theory Horizon, pp. 40-44, 2012(12). 